\title{
O Uso do Método Netnográfico na Pós-Graduação em Administração no Brasil
}

\author{
The Use of Netnographic Method in the \\ Brazilian Management Postgraduate
}

\begin{abstract}
Rafaela Rodrigues Correia
Professora do Programa de Graduação em Economia, Administração de Empresas e Administração Pública. Universidade do Estado de Santa Catarina - UDESC. Florianópolis, SC. Brasil.E-mail: rafinhacorreia@yahoo.com.br
\end{abstract}

\section{Graziela Dias Alperstedt}

Professora do Programa de Pós-Graduação em Administração. Universidade do Estado de Santa Catarina - UDESC. Florianópolis, SC. Brasil.E-mail: gradial@gmail.com

Simone Ghisi Feuerschutte

Professora do Programa de Pós-Graduação em Administração. Universidade do Estado de Santa Catarina - UDESC. Florianópolis, SC. Brasil.E-mail: ghisi.simone@udesc.br

\section{Resumo}

A dinâmica da internet e de suas mídias sociais exige uma constante revisão das metodologias de pesquisa da área. A netnografia é a metodologia aplicada para investigar e interpretar o comportamento do consumidor nas comunidades virtuais. Este artigo apresenta a abordagem netnográfica como ferramenta de análise de informações online em estudos desenvolvidos na Pós-Graduação em Administração no Brasil. Realizou-se um resgate teórico da netnografia e um levantamento bibliográfico de teses e dissertações que utilizaram o método. Os resultados demonstraram que os estudos netnográficos no campo iniciaram-se em 2006, mas foi apenas em 2012 que o método passou a ser amplamente utilizado. Como limitações ao uso do método, é possível destacar a ausência de dados confiáveis e as interpretações superficiais. Mesmo assim, a netnografia apresenta-se como uma ferramenta para analisar grupos virtuais, proporcionando flexibilidade temporal e espacial e possibilitando o surgimento de insights, que se transformam em avanço teóricos na pesquisa em Administração.

Palavras-chave: Netnografia. Métodos Qualitativos. Administração.

\section{Abstract}

The dynamics of the Internet and its social media requires a constant revision of the research methodologies of the area. Netnography is the methodology applied to investigate and interpret consumer behavior in virtual communities. This article presents the netnographic approach as a tool for the analysis of online information in studies developed at the Graduate Program in Administration in Brazil. A theoretical redecoration of the netnography and a bibliographical survey of theses and dissertations that used the method were carried out. The results demonstrated that the fieldwork studies began in 2006, but it was only in 2012 that the method became widely used. As limitations to the use of the method the lack of reliable data and the superficial interpretations stand out. Even so, the netnography is presented as a tool to analyze virtual groups, providing temporal and spatial flexibility and, allowing the emergence of insights, that become theoretical advances in the research in Administration.

Keywords: Netnography. Qualitative Methods. Management. 


\section{INTRODUÇÃo}

As recentes transformações pelas quais a sociedade e a economia têm passado se dão como resultado, em parte, das inovações tecnológicas que o mundo experimenta. As inovações impactam nas relações sociais, inseridas cada vez mais no ambiente virtual, criando novos espaços de interação e comunicação.

Em decorrência desses novos espaços e das novas formas a partir das quais as pessoas passam a se relacionar, uma espécie de cultura de internet foi criada, o que se diferencia em muito das formas até então experimentadas pela sociedade. A esses novos espaços de interação social e econômica mediados pela internet dá-se o nome de ciberespaço.

A possibilidade de se expressar e de se comunicar por meio da internet cria novas demandas. Ao mesmo tempo, são disponibilizadas inúmeras informações que podem criar oportunidade para pesquisadores investigarem dados oriundos de milhões de pessoas, grupos sociais e de suas interações.

É a partir desse movimento, mediado pela tecnologia, que surgem novas metodologias inspiradas ou mesmo adaptadas do ambiente off-line que têm como objetivo possibilitar a exploração das relações entre indivíduos e grupos no ambiente virtual. Entre essas metodologias está a chamada netnografia, objeto de estudo do presente artigo.

A partir da literatura investigada, a netnografia se distingue das demais abordagens de pesquisa a partir de quatro características: baseia-se majoritariamente na análise de textos públicos; concentra-se nas interações particulares entre pessoas no ambiente virtual; parte da análise de arquivos das comunicações virtuais salvas, sendo, portanto, realizadas a posteriori e analisadas de uma forma peculiar de interação privada, que se desenrola no espaço público. Como método para análise de fenômenos sociais, a netnografia, em função de coletar e interpretar dados oriundos do ambiente virtual, se caracteriza pela rapidez, simplicidade e praticidade (NIMROD, 2011).

Apesar de suas limitações como método para investigar relações sociais, destacadas ao longo deste trabalho, observa-se uma crescente utilização do método no contexto da pesquisa em administração no Brasil. Em face disso, objetiva-se no presente artigo analisar o uso da abordagem netnográfica como método de investigação nos estudos desenvolvidos nos Programas de Pós-Graduação em Administração no Brasil.

Para alcançar esse propósito realizou-se uma pesquisa de natureza descritiva e abordagem qualitativa. Partiu-se de um resgate conceitual acerca do método, seguido de levantamento bibliográfico de teses e dissertações no portal Banco de Teses da CAPES, de onde foram selecionados estudos publicados na área da administração que contemplassem o método netnográfico, sem restrição temporal. Espera-se que este trabalho possa despertar para as possibilidades de uso, limitações e desafios metodológicos do chamado método netnográfico, sobretudo no contexto da Pós-Graduação em Administração brasileira.

\section{Da Etnografia À Netnografia}

A criação das comunidades em meio eletrônico, em que consumidores se relacionam e trocam informações sobre marcas, produtos e serviços, passou a ser estudada por pesquisadores a partir de métodos tradicionais de pesquisa. Entre tais métodos, destaca-se a etnografia, originária da Antropologia Social.

Segundo Malinowski (1978), a essência do método etnográfico está em apreender o ponto de vista dos nativos, seu relacionamento com a vida, sua visão de mundo. Do ponto de vista metodológico, a etnografia consiste no processo de observar, participar e conversar com o nativo em suas condições reais de existência, tentando entender e mapear a completude de sua vida, os diferentes princípios, as "lógicas" e os significados por meio dos quais as pessoas atribuem sentido e organizam a "realidade" em que vivem (BARBOSA, 2003).

Especificamente, no que diz respeito à pesquisa do comportamento do consumidor, Elliott e Jankel-Elliott (2003) apontam que o método etnográfico pode ser útil para a compreensão profunda da experiência viva dos consumidores entendidos como seres sociais. Dentre os pressupostos básicos do método etnográfico, os autores destacam: o estudo do comportamento social no mundo real; a crença de que não há como apreender esse comportamento sem entender o mundo simbólico dos sujeitos, alcançando seus pontos de vista e tendo contato com os significados compartilhados em grupo e expressos na linguagem da vida cotidiana; a imersão em um trabalho de campo de longa duração; a 
busca da compreensão das regras locais que orientam a visão de mundo dos atores sociais

Tendo em vista que a etnografia é o estudo descritivo da cultura de uma comunidade, ou de alguns de seus aspectos fundamentais, seu conceito foi transposto ou adaptado para se estudar comunidades e subculturas que existem no ambiente virtual e que, por conseguinte, possuem suas próprias peculiaridades.

Da perspectiva baseada na comunicação $e$ na análise virtual inspirada na pesquisa etnográfica surgiu a denominação netnografia. Essa denominação é também conhecida por outros termos, com a tentativa de popularizar os métodos etnográficos para as pesquisas na internet. Os termos mais proeminentes são: etnografia virtual, webnografia, ciberantropologia e netnografia (FRAGOSO; RECUERO; AMARAL, 2011). Tal variedade de terminologias indica também diferentes procedimentos.

O neologismo "netnografia" (nethnography = net + ethnography) foi originalmente cunhado por um grupo de pesquisadores/as norte americanos/as, quais sejam Bishop, Star, Neumann, Ignacio, Sandusky e Schatz, em 1995, para descrever um desafio metodológico: preservar os detalhes ricos da observação em campo etnográfico usando o meio eletrônico para "seguir os atores" (BRAGA, 2001, p. 5).

Kozinets (2002), um dos autores mais citados nos trabalhos ligados ao tema, refere-se à netnografia como uma ferramenta de pesquisa qualitativa que adapta as técnicas da abordagem etnográfica ao estudo de culturas e comunidades que estão surgindo através da comunicação mediada pelo computador (CMC). Trata-se de uma abordagem capaz de prover informações de simbolismos, significados e padrões de consumo de grupos de consumidores on-line (MISRA; MUKHERJEE; PETERSON, 2008), mostrando-se atraente para estudar as necessidades, desejos, opiniões, atitudes, experiências e interações dos consumidores (LANGER; BECKMAN, 2005).

Hine (2000) chama de etnografia virtual a transferência da tradição de pesquisa etnográfica para os espaços sociais na internet. Todavia, a autora sugere que não há uma mera transposição do método etnográfico por meio do acompanhamento dos atores sociais, uma vez que considera diferenças significativas entre o contexto virtual e o real, principalmente a noção de espaço e tempo. Há que se destacar nesse sentido a impossibilidade de se comparar um método com o outro, dada a natureza da etnografia, caracterizada, sobretudo, pelo contato intersubjetivo entre o pesquisador e o seu objeto, marcado pelo mergulho intenso e prolongado no campo.

A despeito das considerações anteriores, Kozinets $(2002 ; 2010)$ aponta uma série de pontos positivos evidenciados nas pesquisas amparadas no método netnográfico, dentre os quais estão: redução da subjetividade, menor tempo para realização da inserção do pesquisador e menor custo, já que não há deslocamento do pesquisador para um espaço físico. Adicionalmente o espaço virtual pode ser acessado de qualquer local onde haja conexão à internet, o que facilita muito a busca das informações.

Essas vantagens guardam estreita relação com a operacionalidade da pesquisa, pois o pesquisador tem acesso aos discursos praticamente transcritos, encurtando etapas, como a gravação e a transcrição. Mas, em virtude da grande quantidade de informações, o pesquisador necessita filtrar o que é importante e o que é descartável.

Outra vantagem do método destacada por Kozinets (2002), em comparação com outros métodos, como grupos focais e entrevistas pessoais, é que a pesquisa é menos invasiva, visto que o pesquisador pode olhar para seu objeto de pesquisa como se fosse por uma janela. Isto porque a análise é realizada por meio de declarações já existentes no ambiente virtual. Tal destaque do autor parece se referir ao fato de na netnografia não haver o contato pessoal. Nesse sentido, partindo de declarações já publicizadas, não há a necessidade de interferir na realidade do sujeito.

Kozinets (2002, p. 64) destaca, ainda, como pontos positivos da netnografia a simplicidade na coleta de dados: "[...] em uma ruptura brusca com a etnografia tradicional, um trabalho rigoroso de netnografia poderia ser realizado utilizando apenas observação $e$ downloads, sem escrever uma única nota de campo". Nesse caso, o autor não contextualiza sua intenção de pesquisa, tampouco sua base epistemológica, o que pode revelar um aspecto ingênuo, ao comparar a netnografia e suas possibilidades de pesquisa a um método há muito reconhecido.

Dessa forma, a netnografia caracteriza-se como um método capaz de captar as informações em fonte primária, intermediada por dispositivos tecnológicos e como uma forma essencialmente aberta de investi- 
gação. Esse método, de acordo com Rocha, Barros e Pereira (2005) permite que se investigue a realidade por dentro de um grupo no ambiente virtual, gerando conhecimento científico a partir da interpretação do pesquisador acerca do ponto de vista dos investigados.

Apesar de ressaltar suas vantagens, Kozinets (2002; 2006; 2010) destaca as limitações da netnografia. Sobre isso, alerta para as questões éticas envolvidas na definição do que é "público" e do que é "privado" na internet, exigindo do pesquisador cautela e cuidado, informando aos participantes da comunidade estudada sobre o desenvolvimento da pesquisa. Destaca, ainda, uma limitação relevante no método que diz respeito à comunicação não verbal dos entrevistados, uma vez que os dados são apenas textuais. Nesse sentido, informações contraditórias ou mesmo falsas podem comprometer a pesquisa. Sobre essa questão, Montardo e Passerino (2006) afirmam que tal limitação já vem sendo parcialmente superada pela utilização de ferramentas que permitem a transmissão de áudio $e$ vídeo.

O netnógrafo deve estar consciente de que a netnografia observa e recontextualiza conversações intermediadas por computador sem o contato pessoal com os atores pesquisados, como o faz a etnografia (KOZINETS, 2002). Assim, o que pode ser uma vantagem por um lado, acaba por revelar limitações por outro, restringindo os resultados da pesquisa aos dados do ambiente virtual.

Além disso, o fato de ser o método não obstrutivo também gera dúvidas no que diz respeito à questão ética.

Por exemplo: o fato de o pesquisador ter o consentimento informado do grupo leva tal grupo a ter consciência de que estará sendo observado. Isso pode ter um efeito no seu comportamento, enviesando a pesquisa da mesma forma como outra técnica fisicamente presencial o faria. (NOVELI, 2010, p. 9)

Para reduzir possíveis danos na coleta de dados, Dholakhia e Zhang (2004, p. 4) indicam que "[...] é o anonimato do pesquisador que o permite espreitar o ambiente de comunicações online conduzindo uma verdadeira observação não obstrutiva".

A despeito de tais controvérsias, a netnografia é hoje um dos principais métodos adotados para o estudo das comunidades virtuais. Ao contrário de muitas pesquisas tradicionais, segundo Kozinets (2002), ela não força os consumidores a escolherem respostas pré-estabelecidas em um formulário por um pesquisador, oferecendo uma riqueza de informações de base, sobre simbolismos, significados e padrões de consumo dos grupos de consumidores on-line.

O método netnográfico pode, ainda, ser complementar a outras técnicas de coleta de dados de pesquisa, entrevistas, grupos focais e sondagens, a fim de se obter uma compreensão mais ampla sobre determinada população, inclusive em outras áreas do conhecimento como a Educação e a Comunicação Social. Na administração destaca-se o uso do método em pesquisas de marketing, nas quais a netnografia utiliza informações já disponíveis em fóruns virtuais para identificar e compreender as necessidades $e$ influências de decisão de grupos de consumo virtual relevantes (KOZINETS, 2002).

A netnografia parece ser, portanto, uma técnica cada vez mais utilizada e que objetiva esclarecer os comportamentos e experiências dos indivíduos na realidade virtual. De acordo com o autor mais citado nos trabalhos investigados nesse artigo, o método foi concebido como um conjunto distinto de procedimentos destinados a fornecer confiabilidade e conferir consistência em um novo campo de estudos (KOZINETS, 2010).

\section{Etapas do Método Netnográfico}

Este artigo analisou as teses e dissertações sobre netnografia no Brasil e nessas, o autor mais citado é Kozinets. Em função disso, optou-se por esclarecer as etapas desse método pelo autor, juntamente com. De acordo com Kozinets (1997) e reafirmado por Hine (2000), a netnografia mantém as premissas básicas da etnografia. Por isso, ao operacionalizar a metodologia, é necessário, primeiramente, ressaltar os critérios de confiabilidade em relação à escolha dos informantes, levando sempre em consideração o objetivo da pesquisa. É preciso provar que o objeto de pesquisa se refere a um grupo online e que se está de fato estudando uma cultura ou uma comunidade e não apenas examinando uma reunião temporária. Entre as diversas maneiras de aferir essa confiabilidade, estão os critérios propostos por Kozinets (1997):

(1) indivíduos familiarizados entre eles, (2) comunicações que sejam especificamente identificadas e não anônimas, (3) grupos com 
linguagens, símbolos, e normas específicas e (4) comportamentos de manutenção do enquadramento dentro das fronteiras de dentro e fora do grupo (KOZINETS, 1997, p. 9).

Após a validação da escolha dos informantes, Kozinets (1997) descreve alguns procedimentos básicos que colaboram com o pesquisador para que seus objetivos não sejam desviados durante o estudo e para que ocorra a transposição da etnografia para a netnografia. São eles: entrée cultural (entrada ou ingresso), coleta e análise de dados, ética de pesquisa, feedback e checagem de informações com os membros dos grupos.

O primeiro procedimento diz respeito ao entrée cultural, uma espécie de entrada ou ingresso. Trata-se da preparação inicial do pesquisador para o trabalho de campo, fazendo um levantamento de quais tópicos e questões ele pretende analisar. $\mathrm{O}$ pesquisador precisa ter consciência do tema a ser investigado a fim de saber a quem deve se dirigir para obter as informações de que necessita. Depois de selecionada sua amostra, é necessário que o pesquisador saiba em que tipo de comunidades, fóruns e grupos online os sujeitos pesquisados costumam participar; e observe as interações dos sujeitos pesquisados a fim de obter alguma informação sobre a identidade cultural dos indivíduos em foco.

Kozinets (2002) propõe um processo de priorização das comunidades, seguindo alguns critérios: uma segmentação, tópico ou grupo que é mais focado $e$ relevante à pergunta de pesquisa; que tenha maior tráfego de postagens; maior número de postadores de mensagens discretos; possuir dados mais ricos em detalhes ou descrição; e, mais interações entre membros do tipo procurado pelas perguntas da pesquisa.

No segundo procedimento é realizada a coleta e a análise de dados. Para a coleta e análise, três tipos de captura de dados são eficazes, segundo Kozinets (2002). A primeira são os dados coletados e copiados diretamente dos membros das comunidades on-line de interesse, na qual, devido ao grande número de informações e às dúvidas que estas possam causar, é prudente o pesquisador se utilizar de vários tipos filtros para que sobrem apenas informações de relevância para o contorno da pesquisa. A segunda coleta refere-se às informações que o pesquisador observou das práticas comunicacionais dos membros das comunidades, das interações, simbologias e de sua própria participação. A terceira, finalmente, são os dados levantados em entrevistas com os indivíduos, através da troca de e-mails ou em conversas em chats, mensagens instantâneas ou outras ferramentas. O autor recomenda ainda, que se criem categorias para identificar os diferentes tipos de comportamento na internet.

No terceiro procedimento, ética de pesquisa, o autor chama atenção para as questões que devem guiar os questionamentos acerca da ética em netnografia: afinal, os fóruns online são considerados públicos ou privados? Além disso, é preciso que o pesquisador tenha consciência de que embora os dados estejam em território-rede, na realidade, os participantes das comunidades virtuais são efetivamente seus construtores e, não necessariamente pretendem ver seus dados representados em alguma pesquisa. De forma resumida, percebe-se que a questão ética na netnografia está relacionada à privacidade, confidencialidade $e$ apropriação de outras histórias pessoais. A questão da ética de pesquisa pressupóe que o pesquisador deixe claro para o pesquisado como a coleta de dados foi feita e qual é o objetivo do seu estudo. É importante destacar que, ao utilizar informações postadas pelos entrevistados fique claro que será mantido o anonimato e a confidencialidade (KOZINETS, 2002).

Assim, segundo o autor, o caminho eticamente recomendável, é que o pesquisador se identifique e identifique o interesse de sua pesquisa, pedindo as permissões necessárias para o uso das informações obtidas em postagens e em conversas com os participantes das comunidades e fóruns. Além disso, deve garantir confidencialidade e o anonimato aos informantes, tratando-os por pseudônimos e não por seus nomes de usuário.

No quarto procedimento, checagem de informações, o pesquisador apresenta um relatório final de sua pesquisa para alguns dos participantes a fim de que eles possam efetuar uma "avaliação" ou tecerem alguns comentários sobre os resultados alcançados pela pesquisa. Esse procedimento permite que sejam obtidos insights adicionais sejam levantadas fragilidades da pesquisa, estabelecendo-se um contato contínuo entre o pesquisador e os pesquisados. Trata-se de obter o feedback dos envolvidos na pesquisa. Para Kozinets (2002), a checagem de dados com os próprios membros do grupo, legitima e acrescenta credibilidade à pesquisa. 
A Figura 1 sintetiza os procedimentos básicos do método.

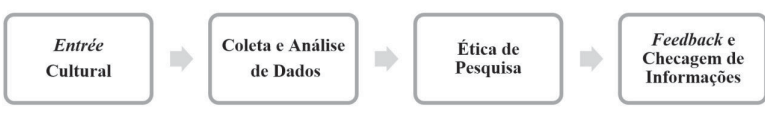

Figura 1: Procedimentos básicos do método netnográfico Fonte: Adaptado de Kozinets (1998)

\section{Procedimentos Metodológicos}

A estratégia utilizada para a coleta de dados do presente estudo, cujo propósito foi analisar a produção acadêmica sobre o método de pesquisa qualitativa em questão - a netnografia - consistiu de levantamento bibliográfico de teses e dissertações publicadas sobre o tema no Brasil, no âmbito dos Programas Pós-Graduação em Administração, sem restrição temporal.

O levantamento das teses e dissertações foi realizado por meio do portal Banco de Teses da CAPES, em outubro de 2016. Foram selecionados estudos publicados nos Programas de Pós Graduação em Administração, em língua portuguesa, nas áreas de administração de empresas e administração e negócios, que tivessem indexadas a palavra-chave "netnografia".

Apesar de não ter sido definida restrição temporal nas buscas, constatou-se, no momento da coleta das teses e dissertações, que o Banco de Teses da CAPES apresentava estudos a partir do ano de 2006, sendo que a partir de 2012 a produção aumentou substancialmente quando comparado com os anos anteriores.

Após a leitura prévia dos resumos, as teses e dissertações encontradas foram analisadas na íntegra, sendo selecionadas aquelas que, de fato, haviam utilizado o método netnográfico. O levantamento resultou em trinta e cinco ocorrências de estudos relacionados à palavra-chave netnografia, sendo cinco teses e trinta dissertações.

Desses trabalhos, cinco foram defendidos anteriormente à criação da Plataforma Sucupira e não foram localizadas, em meio virtual, junto ao site do Programa de Pós-graduação correspondente e em site de busca. Um dos trabalhos estava escrito em inglês e optou-se por desconsiderá-lo; desse modo considerou-se para análise um total de vinte e nove estudos, sendo quatro teses, vinte e quatro dissertações e um artigo retirado da dissertação.
O Quadro 1 expõe os trabalhos que constituíram o foco de análise para o alcance do objetivo deste artigo.

\begin{tabular}{|c|c|c|}
\hline \multicolumn{3}{|c|}{ TESES - 4 ESTUDOS } \\
\hline Ano & Autor & Título \\
\hline 2013 & $\begin{array}{l}\text { Breno de Paula } \\
\text { Andrade Cruz }\end{array}$ & $\begin{array}{l}\text { O Boicote no Comportamento } \\
\text { do Consumidor }\end{array}$ \\
\hline 2013 & $\begin{array}{l}\text { José Jerônimo de } \\
\text { Menezes Lima }\end{array}$ & $\begin{array}{l}\text { Efeitos de comunidades } \\
\text { de prática na capacidade } \\
\text { absortiva em empresas } \\
\text { intensivas em conhecimento }\end{array}$ \\
\hline 2014 & Tiago Savi Mondo & $\begin{array}{l}\text { Tourqual: Proposta de um modelo } \\
\text { de avaliação da qualidade de } \\
\text { serviços em atrativos turísticos }\end{array}$ \\
\hline 2015 & $\begin{array}{l}\text { Wellington } \\
\text { Tavares }\end{array}$ & $\begin{array}{l}\text { Redes Sociais Virtuais como } \\
\text { Espaços para Ações Coletivas: } \\
\text { Possibilidades de Interação e } \\
\text { Organização em Movimentos Sociais }\end{array}$ \\
\hline \multicolumn{3}{|c|}{ DISSERTAÇÕES - 25 ESTUDOS } \\
\hline Ano & Autor & Título \\
\hline 2006 & Daiane Scaraboto & $\begin{array}{l}\text { Comunidades Virtuais Como } \\
\text { Grupos de Referência nos Processos } \\
\text { Decisórios do Consumidor }\end{array}$ \\
\hline 2007 & $\begin{array}{l}\text { Itaquê Ferreira } \\
\text { Cunha }\end{array}$ & $\begin{array}{l}\text { A busca de informações influenciada } \\
\text { por grupos de referências virtuais: } \\
\text { um estudo de caso em uma } \\
\text { comunidade virtual turística }\end{array}$ \\
\hline 2010 & $\begin{array}{l}\text { Vinicius Casella } \\
\text { Abramides }\end{array}$ & Fluidez nos mundos virtuais \\
\hline 2010 & $\begin{array}{l}\text { Roberta } \\
\text { Caldas Siões }\end{array}$ & $\begin{array}{l}\text { Beleza Natural, Comunidade } \\
\text { Virtual e Atores Digitais }\end{array}$ \\
\hline 2010 & $\begin{array}{l}\text { Fabio Manoel } \\
\text { Fernandes de } \\
\text { Albuquerque }\end{array}$ & $\begin{array}{l}\text { Ciberativismo no consumo: } \\
\text { retaliação e vingança em } \\
\text { comunidades virtuais antimarca }\end{array}$ \\
\hline 2011 & $\begin{array}{l}\text { Leticia Ribeiro } \\
\text { Eboli e Luís } \\
\text { Antônio da Rocha }\end{array}$ & $\begin{array}{l}\text { Criação Coletiva na Web } \\
\text { 2.0: um Estudo de Casos }\end{array}$ \\
\hline 2012 & $\begin{array}{l}\text { Izabelle Alice } \\
\text { Santos Pessanha } \\
\text { Soares }\end{array}$ & $\begin{array}{l}\text { Blogs como referência para o } \\
\text { consumo: um estudo exploratório } \\
\text { das interações sociais e do } \\
\text { comportamento feminino }\end{array}$ \\
\hline 2012 & $\begin{array}{l}\text { Everaldo Marcelo } \\
\text { Souza da Costa }\end{array}$ & $\begin{array}{l}\text { Comportamento do consumidor } \\
\text { tecnológico no setor educacional }\end{array}$ \\
\hline 2012 & $\begin{array}{l}\text { Sergio Souza } \\
\text { Xavier }\end{array}$ & $\begin{array}{l}\text { Comunidades Virtuais: A } \\
\text { importância da interação } \\
\text { no aspecto da relação de } \\
\text { consumo no ciberespaço }\end{array}$ \\
\hline 2012 & $\begin{array}{l}\text { Lorena Magalhães } \\
\text { Freire da Silva }\end{array}$ & $\begin{array}{l}\text { Valores comportamentais na } \\
\text { preferência de uso das redes sociais }\end{array}$ \\
\hline 2012 & $\begin{array}{l}\text { Aldomar } \\
\text { Nascimento } \\
\text { Júnior }\end{array}$ & $\begin{array}{l}\text { Com a boca no Twitter: a } \\
\text { cocriação e a colaboração } \\
\text { impactando no sucesso do } \\
\text { marketing boca a boca online }\end{array}$ \\
\hline
\end{tabular}




\begin{tabular}{|c|c|c|}
\hline 2013 & $\begin{array}{l}\text { Gisele Rosner } \\
\text { Chouin }\end{array}$ & $\begin{array}{l}\text { Interações, significados e práticas } \\
\text { do vegetarianismo na mídia } \\
\text { social: um estudo netnográfico }\end{array}$ \\
\hline 2013 & $\begin{array}{l}\text { Thiago Assuncao } \\
\text { de Moraes }\end{array}$ & $\begin{array}{l}\text { E-tribes: um estudo do } \\
\text { comportamento dos } \\
\text { consumidores à luz da teoria } \\
\text { das representações sociais }\end{array}$ \\
\hline 2013 & $\begin{array}{l}\text { Douglas Renato } \\
\text { Adade }\end{array}$ & $\begin{array}{l}\text { "Comida di buteco": o botequim, } \\
\text { um pedaço da alma carioca, em } \\
\text { uma iniciativa de construção de } \\
\text { comunidade virtual de marca }\end{array}$ \\
\hline 2013 & $\begin{array}{l}\text { Camila Uliana } \\
\text { Donna }\end{array}$ & $\begin{array}{l}\text { As redes sociais digitais no } \\
\text { cotidiano das pessoas: um } \\
\text { estudo sobre a interpretação } \\
\text { dos símbolos organizacionais }\end{array}$ \\
\hline 2013 & $\begin{array}{l}\text { Marcos Alexandre } \\
\text { Lima de Oliveira }\end{array}$ & $\begin{array}{l}\text { Compras coletivas de } \\
\text { serviços turísticos: quando } \\
\text { o barato custa caro }\end{array}$ \\
\hline 2014 & $\begin{array}{l}\text { Maryelle Carolina } \\
\text { Goncalves Soares }\end{array}$ & $\begin{array}{l}\text { Consumo feminino de moda } \\
\text { e influências sociais: dos blogs } \\
\text { às consumidoras finais }\end{array}$ \\
\hline 2014 & $\begin{array}{l}\text { John Daniel } \\
\text { Tankersley }\end{array}$ & $\begin{array}{l}\text { Uma análise netnográfica da } \\
\text { organização da subcultura de } \\
\text { consumo na rede social: caso caloi }\end{array}$ \\
\hline 2014 & $\begin{array}{l}\text { Karen Miranda } \\
\text { Chuequer }\end{array}$ & $\begin{array}{l}\text { A manifestação do } \\
\text { consumidor insatisfeito nas } \\
\text { comunidades virtuais: uma } \\
\text { abordagem netnográfica }\end{array}$ \\
\hline 2014 & $\begin{array}{l}\text { Chalum Bezerra } \\
\text { Batista }\end{array}$ & $\begin{array}{l}\text { O Computador e a Caixa Mágica: } \\
\text { análise da interação entre o Banco } \\
\text { do Brasil e os seus clientes em sua } \\
\text { fanpage, baseada na perspectiva } \\
\text { dramatúrgica de Erving Goffman }\end{array}$ \\
\hline 2014 & $\begin{array}{l}\text { Ana Beatriz } \\
\text { Campos Neves }\end{array}$ & $\begin{array}{l}\text { Dinâmicas de influência e discursos } \\
\text { sobre o processo de cessação } \\
\text { tabagista nas comunidades online } \\
\text { de apoio ao abandono do cigarro }\end{array}$ \\
\hline 2014 & $\begin{array}{l}\text { Christian Fassel } \\
\text { Tudesco }\end{array}$ & $\begin{array}{l}\text { Análise das variáveis da } \\
\text { experiência do consumidor de } \\
\text { produtos hedônicos através das } \\
\text { interações e conteúdo gerado } \\
\text { por consumidores e entusiastas } \\
\text { de vinho: Um comparativo } \\
\text { entre duas vinícolas chilenas }\end{array}$ \\
\hline 2015 & $\begin{array}{l}\text { Eduardo } \\
\text { Lorea Leite }\end{array}$ & $\begin{array}{l}\text { Product placement na vida } \\
\text { real: como consumidores } \\
\text { cocriam valor com marcas } \\
\text { em narrativas fotográficas } \\
\text { egocêntricas nas redes sociais }\end{array}$ \\
\hline 2015 & $\begin{array}{l}\text { Andre de Castilho } \\
\text { Costa Pinto }\end{array}$ & $\begin{array}{l}\text { Até logo facebook - um estudo } \\
\text { do processo de abandono } \\
\text { de um site de rede social }\end{array}$ \\
\hline 2015 & $\begin{array}{l}\text { Larissa de } \\
\text { Siqueira } \\
\text { Fernandes }\end{array}$ & $\begin{array}{l}\text { A influência das interações sociais } \\
\text { online na adesão ao tratamento } \\
\text { de doentes crônicos no brasil e } \\
\text { as possibilidades de criação de } \\
\text { serviços pela indústria farmacêutica }\end{array}$ \\
\hline
\end{tabular}

Quadro 1: Trabalhos que constituíram o foco de análise Fonte: Bases de dados consultadas
Para a análise completa dos trabalhos foram definidas categorias analíticas, tendo como base os conceitos apresentados na revisão teórica realizada sobre o método netnográfico e os dados gerais sobre as publicações. O Quadro 2 expõe as categorias de análise definidas.

\begin{tabular}{|l|l|}
\hline \multicolumn{1}{|c|}{ CATEGORIA } & \multicolumn{1}{c|}{ CRITÉRIOS DE ANÁLISE } \\
\hline $\begin{array}{l}\text { Informações } \\
\text { gerais do trabalho }\end{array}$ & $\begin{array}{l}\text { Instituição/Região de origem } \\
\text { Orientador } \\
\text { Ano de publicação }\end{array}$ \\
\hline $\begin{array}{l}\text { Fundamentos } \\
\text { teórico-empíricos }\end{array}$ & $\begin{array}{l}\text { Principais autores utilizados para definir/ } \\
\text { orientar a aplicação do método } \\
\text { Linha de pesquisa } \\
\text { Justificativa para uso do método } \\
\text { Forma de aplicação do método }\end{array}$ \\
\hline Avaliação & $\begin{array}{l}\text { Limitações encontradas } \\
\text { com o uso do método } \\
\text { Aspectos favoráveis quanto } \\
\text { ao uso do método }\end{array}$ \\
\hline
\end{tabular}

Quadro 2 - Categorias e critérios de análise

Fonte: Elaborado pelos autores deste artigo

Na categoria "informações gerais do trabalho", foi investigada a instituição à qual o autor pertencia no período em que os trabalhos foram realizados, o orientador $e$ o respectivo ano de publicação.

Em "fundamentos teórico-empíricos" buscou-se apresentar os principais autores considerados para definir e orientar a aplicação do método, o que possibilitou verificar que poucos pesquisadores discutem a netnografia, cabendo aos demais estudiosos apenas aceitar e reproduzir os conceitos. Na referida categoria também se apresentou as linhas de pesquisa às quais estão vinculadas as teses e dissertações, objetivando caracterizar as abordagens teóricas dos trabalhos. $\mathrm{Na}$ sequência, foram investigadas as justificativas apresentadas para o uso do método, ou seja, o motivo que guiou a escolha de seus autores.

Por fim, considerou-se a categoria "avaliação", que representa uma avaliação dos próprios autores dos artigos em relação à utilização do método. Nesse sentido, foi possível traçar um paralelo com o referencial teórico encontrado, apresentando-se as limitações e os aspectos favoráveis da netnografia como método de pesquisa nos Programas de Administração.

\section{Resultados do Estudo}

Dos vinte e nove trabalhos que utilizaram a netnografia, o levantamento permitiu identificar que: 
das quatro teses, uma é vinculada à Fundação Getúlio Vargas de São Paulo (FGV-SP), uma à Universidade Federal de Santa Catarina (UFSC), uma à Universidade Federal de Minas Gerais (UFMG) e uma a Universidade do Vale do Rio dos Sinos (UNISINOS). Já quanto às vinte e cinco dissertações, seis têm origem na Universidade Federal do Rio de Janeiro (UFRJ), duas na Universidade da Amazônia (UNAMA), duas na Universidade Federal do Rio Grande do Sul (UFRGS), duas na Universidade Federal do Espírito Santos (UFES), duas na Universidade Federal da Paraíba (UFBP), duas na Universidade Federal de Pernambuco (UFPE) e as nove restante estão distribuídas igualmente entre a Pontíficia Universidade Católica de Minas Gerais (PUC-MG), Faculdade Novos Horizontes, FGV-SP, Fundação Getúlio Vargas do Rio de Janeiro (FGV-RJ) Universidade do Grande Rio (UNIGRANRIO), Universidade de Santa Cruz do Sul (UNISC), Pontíficia Universidade Católica do Rio Grande do Sul (PUC-RS), Fundação Instituto Capixaba de Pesquisas em Contabilidade, Economia e Finanças (FUCAPE) e a Universidade de Fortaleza (UNIFOR).

\subsection{Análise das Informações Gerais dos Trabalhos}

A respeito do ano de publicação, os resultados mostram que os trabalhos começaram a figurar no ambiente acadêmico, dentro dos Programas de Administração, a partir do ano de 2006. As teses datam de 2012, 2013 e 2015, já as dissertações de 2006 a 2015. Esta informação demonstra o crescimento de estudos que abordam o método netnográfico (Gráfico 1).

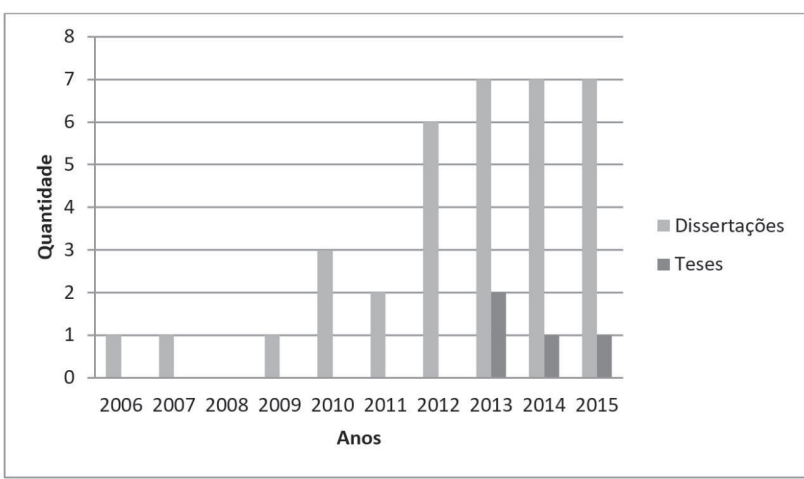

Gráfico 1: Evolução do estudo do Método Netnográfico no Brasil em Programas de Administração

Fonte: Elaborado pelos autores deste artigo a partir da base de dados consultada
$\mathrm{Na}$ análise dos orientadores das teses e dissertações verificou-se uma pequena centralização de pesquisadores de uma mesma instituição. Letícia Moreira Casotti, da UFRJ, orientou duas dissertações e Maribel Carvalho Soares, também da UFRJ orientou duas dissertações.

A participação de poucas IES brasileiras e o restrito número de autores e orientadores envolvidos demonstram uma polarização significativa de instituições em torno do uso da netnografia na produção de trabalhos nos Programas de Administração. Tal constatação corrobora com o fato de que o método netnográfico ainda é pouco utilizado pelos pesquisadores nos Programas de Administração no Brasil.

\subsection{Fundamentos Teórico-Empíricos dos Trabalhos Analisados}

Nos fundamentos teóricos abordados pelos trabalhos o autor que mais se destacou foi Robert V. Kozinets administrador e antropólogo, professor da York University. Atribui-se à Kozinets o desenvolvimento do método na década de noventa durante sua tese de doutorado, assim como as primeiras publicações sobre o tema. Nesse domínio, destacam-se citações aos seus dois artigos clássicos "On netnography: initial reflections on consumer research investigations of cyberculture", de 1998, no qual ele apresenta a netnografia e seus pressupostos essenciais; $e$ "The field behind the screen: using netnography for marketing research in online communities", de 2002, em que os aspectos de operacionalização começam a ser detalhados. Além disso, as demais publicações do referido autor com seus colegas de trabalho são frequentemente mencionadas.

$\mathrm{O}$ autor vem sendo largamente citado quando os pesquisadores dos trabalhos buscam caracterizar o caminho metodológico percorrido, principalmente quanto aos aspectos de coleta de dados e definição dos sujeitos abordados em suas pesquisas.

As linhas de pesquisa dos Programas de Pós-Graduação em Administração aos quais os autores dos trabalhos pertenciam à época de publicação são: "Estudos organizacionais" (duas dissertações e uma tese); "Gestão e estratégia" (seis dissertações e uma tese); "Marketing" (quatorze dissertações); "Subjetividade na gestão de organizações" (uma dissertação); "Produção e desenvolvimento" (uma tese); "Com- 
petitividade e relações interorganizacionais" (uma dissertação e uma tese) $e$ "Operações, tecnologia $e$ logística" (uma dissertação).

Quanto à justificativa para uso do método, de maneira geral os autores buscaram traçar uma relação com o objetivo do estudo, apresentando-o e tentando tecer alguns comentários com os conceitos de netnografia de Kozinets, para analisar o consumidor em uma comunidade online e, questionar de que forma o ambiente virtual influencia o comportamento do consumidor no ciberespaço; avaliar as interações e as dinâmicas presentes em redes sociais e blogs; analisar a subcultura de consumo; e explorar os aspectos relacionados ao consumo como forma de transmissão de significados simbólicos.

A aplicação do método foi ilustrada e descrita de forma detalhada tanto nas dissertações quanto nas teses. O método utilizado foi aquele desenvolvido por Kozinets em 1998 e suas adaptações. O objetivo de estudo é definido, assim como o tipo de comunidade online e/ou redes sociais que os sujeitos pesquisados costumam participar: Facebok, Twitter, Blogs, Fanpages, Tripadvisor, dentre outros. Na sequência, os pesquisadores se inserem nessas comunidades para a realização do levantamento de dados. Vale observar que nas teses o volume de informações é maior.

Uma das teses analisadas pesquisou mais de 50 mil comentários em português de um site de avaliação de destinos turísticos. Segundo Kozinets (2002, 2010) isso é possível porque o método netnográfico não depende de um mecanismo de registro de dados, pois os depoimentos e as entrevistas netnográficas já estão transcritos, o que, por conseguinte, reduz a subjetividade.

Quanto à etapa relacionada à ética da pesquisa, alguns autores escreveram como limitação ao método a impossibilidade de utilizar dados sem o aval do usuário ou da comunidade. Outros utilizaram os dados sem o consentimento ou mesmo sem informar aos participantes da comunidade estudada, sobre o desenvolvimento da pesquisa, justificando nos trabalhos esta postura em função da limitação de tempo para elaboração e defesa dos trabalhos, além do viés que poderia ser gerado nas atitudes e discursos dos integrantes ao saberem que estavam sendo observados. Acerca dessa questão, Dholakhia e Zhang (2004, p. 4) indicam que para reduzir possíveis danos na coleta de dados "é o anonimato do pesquisador que o permite espreitar o ambiente de comunicações online conduzindo uma verdadeira observação não obstrutiva”. Em todos os estudos o anonimato dos e a confidencialidade dos participantes foram preservados. Por outro lado, Ward (1999) defende um processo mais interativo na condução da coleta de dados no estudo netnográfico, realizando-se por meio de entrevistas com os membros participantes da comunidade para saber suas opiniões.

Um tópico importante que emergiu no tocante a ética foi a confiança em mensagens, post e avaliações $e$ nas interpretações dos pesquisadores. Isto porque, $\mathrm{o}$ usuário participante da comunidade pode deliberadamente postar um comentário sem nenhuma fundamentação ou experiência prévia, o que pode trazer sérias limitações para a pesquisa, distorcendo seus resultados. Em razão de a netnografia estar baseada na análise de materiais textuais, Kozinets (2002) aconselha que se deve adaptá-la à abordagem de George Mead, segundo a qual a última unidade de análise não se restringe à pessoa, mas ao seu comportamento. Em sua teoria, Kozinets (2002), também recorre à filosofia da linguagem de Ludwig Wittgenstein, que analisa o texto como uma ação social - um ato comunicativo ou um "jogo de linguagem".

Além do mais, na abordagem netnográfica o ato comunicativo é diferente daquele observado pela etnografia tradicional, pois é mediado por computador, está disponível publicamente, é gerado em forma de texto escrito, $e$ as identidades dos participantes da conversação são mais difíceis de serem discernidas. Essas características por si só trazem vantagens e desvantagens. Em relação à etapa final, feedback e checagem, percebeu-se que alguns estudos simplesmente a ignoraram. Outros estudos, que utilizaram entrevistas como método complementar à netnografia, realizaram a checagem ao longo das entrevistas.

A etapa de checagem era apresentada na etapa de ingresso, ou seja, nos trabalhos que utilizaram essa etapa como forma de gerar insights os autores alertaram aos participantes que ao final da pesquisa o relatório gerado seria enviado a alguns deles com o objetivo de validar as interpretações relativas às observações realizadas e comparar suas opiniões com o resultado final. Este procedimento, segundo os pesquisadores, estabeleceu uma coerência entre as 
reflexões resultantes da pesquisa e a realidade daqueles que vivenciam o fenômeno investigado.

\subsection{Aspectos Restritivos e Facilitadores na Adoção do Método}

Todas as teses e dissertações analisadas mencionaram aspectos favoráveis ou limitações em relação à operacionalização do método netnográfico. O Quadro 3 expõe as limitações e os aspectos favoráveis elencados nos trabalhos que constituíram o foco de análise do estudo que gerou este artigo.

\begin{tabular}{|l|l|}
\hline \multicolumn{1}{|c|}{ LimitaçõEs } & \multicolumn{1}{c|}{ AsPECTOS FAVORÁvEIS } \\
\hline Restrição do escopo da pesquisa & $\begin{array}{l}\text { Facilidade de coleta e de } \\
\text { extração dos dados }\end{array}$ \\
\hline $\begin{array}{l}\text { Ausência de dados confiáveis } \\
\text { que identifiquem os informantes }\end{array}$ & Redução da subjetividade \\
\hline Interpretações superficiais & $\begin{array}{l}\text { Menor tempo para realização } \\
\text { da inserção do pesquisador }\end{array}$ \\
\hline $\begin{array}{l}\text { Impossibilidade de } \\
\text { generalização dos resultados }\end{array}$ & Menor custo \\
\hline Falsa noção de neutralidade & $\begin{array}{l}\text { Não obstrutiva quando } \\
\text { comparada com } \\
\text { outros métodos }\end{array}$ \\
\hline $\begin{array}{l}\text { Ausência de outras } \\
\text { fontes de dados }\end{array}$ & $\begin{array}{l}\text { Robusta ferramenta para } \\
\text { analisar os grupos online }\end{array}$ \\
\hline $\begin{array}{l}\text { Comunicação não verbal dos } \\
\text { entrevistados não foi capturada }\end{array}$ & $\begin{array}{l}\text { Insights adicionais } \\
\text { podem ser gerados }\end{array}$ \\
\hline
\end{tabular}

Quadro 3: Fatores restritivos e facilitadores do uso da netnografia

Fonte: Elaborado pelos autores deste artigo a partir da base de dados consultada

A análise de comunidades virtuais indica um grande fluxo de informações dinâmico e intenso, por conta da grande quantidade de membros. Tal fato dificulta a coleta dos dados e demanda do pesquisador uma habilidade de interpretação mais apurada, podendo ocasionar análises superficiais. No ambiente virtual esse fluxo de informações precisa ser canalizado, para que o pesquisador não se perca em meio a tantos dados, o que impossibilita uma maior abrangência do estudo, não sendo possível, portanto, generalizar os resultados.

De posse dos textos, posts ou comentários é que foi realizada a análise dos dados. A comunicação verbal, em muitos dos trabalhos, não foi capturada, configurando na ausência de outras fontes de dados, o que pode gerar um viés nos resultados, pois não há como saber se a informação coletada reflete o pensamento e o comportamento dos usuários da comunidade, muito menos se o usuário ou a experiência de fato existem, o que gera uma falsa sensação de neutralidade.

Já sobre a limitação de se restringir ao material textual, Kozinets (1998) e Dholakia e Zhang (2004) ressaltam que o destaque desse método é a conversação gerada por meio do texto escrito, não o comportamento real dos indivíduos que compõem a comunidade. Os pesquisadores podem ampliar as pesquisas netnográficas com utilização maior de outras modalidades de informação, tais elementos visuais e elementos sonoros. Nesse caso, abre-se espaço para a análise de figuras, charges, fotos e vídeos, para complementar os elementos textuais (GARCIA et al., 2009).

Quanto à comunicação não verbal dos entrevistados Kozinets (1998), confirma tal limitação, uma vez que os dados são apenas textuais. Montardo e Passerino (2006), entretanto, afirmam que essa restrição já vem sendo parcialmente superada pela utilização de ferramentas que permitem a transmissão de áudio e vídeo. Na análise dos trabalhos, dentre os posts coletados, poucos foram os que utilizaram recursos audiovisuais ou entrevistas, predominando os elementos textuais.

A falta de segurança em relação à identidade dos membros do grupo estudado decorre da possibilidade de se criar perfis nas redes sociais com dados não verídicos. Esta limitação pode ser amenizada pela adoção de procedimentos específicos pelo pesquisador, como a filtragem dos informantes dentro das comunidades virtuais.

Dholakia e Zhang (2004) consideram o anonimato inerente às comunidades virtuais uma vantagem, pois permite que os informantes estejam mais abertos e mais verdadeiros em relação aos seus pensamentos. Além disso, tal condição possibilita o anonimato também do pesquisador que, em uma estratégia conhecida como lurking, pode "espionar" algumas comunidades interessantes para selecionar aquela que lhe servirá como campo de pesquisa. Isto pode ser visto como uma vantagem do método, uma vez que os sujeitos normalmente se predispõem a falar mais livremente sobre assuntos delicados, que poderiam gerar inibição em uma conversa tradicional que exija a sua identificação (LANGER; BECKMAN, 2005). 
O Quadro 4 ilustra resumidamente as limitações e os fatos geradores dos aspectos restritivos encontrados pelos autores dos trabalhos pesquisados. Ademais, são sugeridas alternativas com base na literatura para minimizar tais limitações.

\begin{tabular}{|l|l|l|}
\hline \multicolumn{1}{|c|}{ LIMITAÇÃo } & FATO GERADOR & \multicolumn{1}{|c|}{ ALTERNATIVA } \\
\begin{tabular}{|l|l|l|} 
Ausência de \\
dados confiáveis de \\
que identifique \\
os informantes
\end{tabular} & $\begin{array}{l}\text { Possibilidade de } \\
\text { criar falsos perfis }\end{array}$ & $\begin{array}{l}\text { específicos na } \\
\text { filtragem dos } \\
\text { informantes dentro } \\
\text { das comunidades } \\
\text { virtuais }\end{array}$ \\
\hline $\begin{array}{l}\text { Interpretações } \\
\text { superficiais }\end{array}$ & $\begin{array}{l}\text { Grande fluxo de } \\
\text { informações }\end{array}$ & $\begin{array}{l}\text { Necessidade } \\
\text { de habilidade } \\
\text { interpretativa do } \\
\text { pesquisador }\end{array}$ \\
\hline $\begin{array}{l}\text { Ausência de } \\
\text { outras fontes } \\
\text { de dados }\end{array}$ & Comunidade online & $\begin{array}{l}\text { Análise de } \\
\text { figuras, charges, } \\
\text { fotos e vídeos }\end{array}$ \\
\hline $\begin{array}{l}\text { Comunicação } \\
\text { não verbal dos } \\
\text { entrevistados não } \\
\text { foi capturada }\end{array}$ & $\begin{array}{l}\text { Recorte comunicacional } \\
\text { apenas textual }\end{array}$ & $\begin{array}{l}\text { Entrevistas em } \\
\text { tempo real (Skype) }\end{array}$ \\
\hline
\end{tabular}

Quadro 4: Limitação, fato gerador e alternativa

Fonte: Elaborado pelos autores deste artigo a partir da base de dados consultada

A despeito de suas limitações, o método netnográfico permite maior facilidade na coleta e extração dos dados, proporcionada pela natureza eletrônica dos dados, eliminando a necessidade de transcrição e de dependência da memória do entrevistador, o que torna a pesquisa menos custosa, já que não há o deslocamento do pesquisador para um espaço físico. O espaço virtual pode ser acessado de qualquer local onde haja acesso à Internet, o que facilita muito o acesso às informações necessárias. Nesse sentido, Sade-Beck (2004) considera a grande quantidade de informações como uma vantagem para o pesquisador.

Outro aspecto positivo é que o pesquisador consegue se inserir mais facilmente no ambiente a ser observado e ter acesso a um discurso mais espontâneo e natural, o que reduz a subjetividade e proporciona o equacionamento de poder entre pesquisador e pesquisado. Segundo Kozinets (2002), em comparação com outros métodos, como grupos focais e entrevistas pessoais, a pesquisa é menos invasiva, visto que o pesquisador pode olhar para seu objeto de pesquisa como se fosse por uma janela, além de mais natural, o ambiente não é criado pelo pesquisador como em outros métodos conhecidos.

O método netnográfico, portanto, apresenta-se como um recurso viável para analisar os grupos que se formam no ambiente virtual, proporcionando flexibilidade temporal e espacial e o surgimento de insights que se transformam em avanço teóricos.

\section{Considerações Finais}

O presente artigo se propôs a caracterizar o método netnográfico e seu uso nas teses e dissertações nos Programas de Pós-graduação em Administração no Brasil. Optou-se por desenvolver uma pesquisa descritiva, de abordagem qualitativa, na forma de uma pesquisa bibliográfica.

Primeiramente foi exposto o conceito de netnografia e as diferenças em relação ao método etnográfico. Destaca-se que a abordagem foi centrada na literatura pertinente $e$ o trabalho aqui apresentado possui o intuito de trazer à tona esse método que se diz novo em função do ambiente a partir do qual extrai os dados. Na sequência, foram apresentadas as etapas do método netnográfico, de acordo com o autor mais citado nos trabalhos analisados. A contribuição do artigo consistiu em fazer um levantamento das teses e dissertações que fizeram uso da pesquisa netnográfica junto aos Programas de Pós-Graduação em Administração no Brasil.

Os resultados demonstraram que os estudos netnográficos no Brasil, no campo da Administração, tiveram início aproximadamente em 2006 quando os primeiros trabalhos de pós-graduação foram realizados. A utilização desse método ganhou força a partir de 2012, principalmente nas linhas de pesquisas relacionadas à "Marketing" e a "Gestão e Estratégia".

Nas teses de doutorado e dissertações de mestrado percebeu-se uma atenção à justificativa de utilização do método, bem como a sua relação com o sujeito pesquisado. Os autores descreveram de forma detalhada as etapas do método, inclusive suas limitações, buscando revelar transparência, confiança e validade na pesquisa.

A aplicabilidade do método não mostrou ser um problema, posto que todos os autores utilizaram 
a metodologia desenvolvida por Kozinets. Em alguns trabalhos observou-se a utilização de outros métodos para complementar a análise do objeto de pesquisa, como se sugere pela literatura.

Como principais limitações ao uso do método destacam-se a ausência de dados confiáveis e as interpretações superficiais, devido à possibilidade de se criar perfis falsos e ao grande fluxo de informações disponibilizado no ambiente virtual, respectivamente. Essas restrições são inversamente proporcionais à habilidade de filtragem de comunidades e interpretação das informações por parte do pesquisador.

Quanto aos aspectos positivos destacam-se a maior facilidade na coleta e extração dos dados, proporcionada pela natureza eletrônica das informações, o que torna a pesquisa menos custosa e o menor tempo para inserção do pesquisador no ambiente a ser observado, possibilitando acesso a um discurso já pronto o que, segundo os autores, pode reduzir a subjetividade. Por outro lado, esse mesmo aspecto pode levar à superficialidade da pesquisa citada anteriormente, na medida em que se vale de uma objetivação nem sempre favorável à compreensão das relações sociais.

A despeito da netnografia, como outros métodos de pesquisa, apresentar limitações, entende-se que se revela, a partir dos trabalhos analisados, eficiente e adequada como método de investigação para pesquisar o comportamento do consumidor em ambiente virtual. Isso pode revelar o caráter epistemológico atribuído ao método, ausente no discurso de seus defensores.

Espera-se, entretanto, que os resultados e a análise apresentada neste artigo possam contribuir para a elucidação do método netnográfico, assim como para despertar novas possibilidades de pesquisas que venham a utilizá-lo, considerando o crescimento e a diversidade das redes sociais e outros mecanismos virtuais de interação, em que indivíduos e grupos muitas vezes manifestam-se de forma espontânea. Apesar de suas críticas, não é de se negar que muitas pessoas interagem preponderantemente por intermédio da internet.

Nesse sentido, a partir das possibilidades que apresenta, a netnografia pode oferecer uma multiplicidade de outras aplicações acadêmicas, auxiliando pesquisadores na compreensão de vários fenômenos e temas, como o comportamento do consumidor, com- petências individuais, liderança e gestão de pessoas, inovação, estabelecimento de redes, entre outros.

\section{REFERÊNCIAS}

BARBOSA, L. Marketing Etnográfico: colocando a Etnografia em seu Devido Lugar. Revista de Administração de Empresas, [S.I.], v. 43, n. 3, p. 100105, 2003. Disponível em: <http://www.scielo.br/pdf/rae/ v43n3/v43n3a07.pdf>. Acesso em: 16 out. 2016.

BRAGA, A. Usos e consumos de meios digitais entre participantes de weblogs: uma proposta metodológica. In: XVI ENCONTRO DA COMPÓS, na UTP, Curitiba, PR, 2007. Anais... Curitiba, PR, 2007. Disponível em: <http://www.compos.org.br/data/ biblioteca_162.pdf>. Acesso em: 16 out. 2016.

DHOLAKIA, U.; BAGOZZI, R.; PEARO, L. A social influence model of consumer participation in network and small-group-based virtual community. International

Journal of Research in Marketing, [S.I.] v. 21, n. 3, p. 241-263, 2004. Disponível em: < http://www-bcf.usc. edu/ douglast/620/bettina1.pdf $>$. Acesso em: 16 ouy. 2016.

\section{ELLIOTT, R.; JANKEL-ELLIOTT, N. Using}

ethnography is strategic consumer research.

Qualitative Market Research, [S.I.] v. 6, n. 4, 2003.

Disponível em: <http://www.emeraldinsight.com/doi/ abs/10.1108/13522750310495300 >. Acesso em: 16 out. 2016.

FRAGOSO, S.; RECUERO, R.; AMARAL, A. Métodos de

pesquisa para internet. Porto Alegre: Sulina, 2011. 239 p.

GARCIA, A. C. et al. Ethnographic Approaches to the Internet and Computer-Mediated Communication.

Journal of Contemporary Ethnography, v.38, n.1, p.52-84, 2009. Disponível em: <http://jce.sagepub.com/ content/38/1/52.abstract>. Acesso em: 16 out. 2016.

HINE, C. Los Objetos Virtuales de la Etnografía.

Etnografía Virtual, [S.I.], Editorial UOC, 2000.

KOZINETS, R. V. Netnography: doing ethnographic research online. Sage Publications, 2010 
Click to Connect: Netnography and Tribal

Advertising, Journal Of Advertising Research, v. 46, n. 3, p. 279-288, Business Source Premier, 2006. Disponível em: <http://faculty.msb.edu/arl45/studentinfo/alt/ Click\%20to\%20Connect.pdf $>$. Acesso em: 16 out. 2016.

The Field Behind the Screen: Using Netnography for Marketing Research in Online Communities. Journal of Marketing Research, [S.l.], v.39, fev. p. 61-72, 2002. Disponível em: <http://www.nyu.edu/pages/classes/bkg/ methods/netnography.pdf> . Acesso em: 16 out. 2016.

On netnography: Initial Reflections on Consumer Research Investigations of Cyberculture. Advances in Consumer Research, Evanston, Illinois, v. 25. p. 366371, 1998. Disponível em: <http:/www.acrwebsite.org/ volumes/8180/volumes/v25/NA-25 > . Acesso em: 16 out. 2016.

I want to believe: a Netnography of the

X-Philes Subculture on Consumption. Advances in

Consumer Research, [S.1.], v. 24. n. 1, p. 470-475, 1997. Disponível em: <https://www.researchgate. net/publication/285771984_I_want_to_believe_A_ netnography_of_the_X-philes'subculture_of_ consumption>. Acesso em: 16 out. 2016.

LANGER, R.; BECKMAN, S. C. Sensitive research topics: netnography revisited. Qualitative Market Research:

An International Journal, [S.1.], v. 8, n. 2, p. 189-203, 2005. Disponível em: <http:/www.emeraldinsight.com/ doi/pdfplus/10.1108/13522750510592454>. Acesso em: 16 out. 2016.

MALINOWSKI, B. K. Argonautas do Pacífico

Ocidental: um relato do empreendimento e da aventura dos nativos no arquipélago da Nova Guiné. 2. ed. São Paulo: Abril Cultural, 1978.

MISRA, R.; MUKHERJEE, A.; PETERSON, R. Value creation in virtual communities: the case of a healthcare web site. International Journal of Pharmaceutical and Healthcare Marketing, [S.I.], v. 2, n. 4, p. 321-337, 2008. Disponível em: <http://www.emeraldinsight.com/ doi/pdfplus/10.1108/17506120810922358> . Acesso em: 16 out. 2016.
MONTARDO, S. P.; PASSERINO, L. Estudo dos blogs a partir da netnografia: possibilidades e limitações.

RENOTE, Revista Novas Tecnologias na Educação, [S.l.], v. 4, n.2 2006. Disponível em: < http://seer.ufrgs. br/renote/article/view/14173/8102> . Acesso em: 16 out. 2016.

NIMROD, G. The fun culture in seniors' online communities. The Gerontologist, [S.l.], v. 51, n. 2, p. 226-237, 2011. Disponível em: <http://gerontologist. oxfordjournals.org/content/51/2/226.abstract $>$. Acesso em: 16 out. 2016.

NOVELI, M. Do Off-line para o Online: a Netnografia como um Método de Pesquisa ou o que pode acontecer quando tentamos levar a Etnografia para a Internet?

Revista Organizações em Contexto, [S.l.], v. 6, n.12. p. 107-133, 2010. Disponível em: < http://www.metodista. br/revistas/revistas-metodista/index.php/OC/article/ view/2697/2640>. Acesso em: 16 out. 2016.

ROCHA, E. P. Q.; BARROS, C.; PEREIRA, C. Perspectivas do método etnográfico em marketing: consumo, comunicação e netnografia. In: ENCONTRO DA ANPAD, 29. Brasília: ANPAD. 1. 2005. Anais... Brasília: ANPAD. 2005. 1 CD-ROM. Disponível em: <http://www.anpad. org.br/diversos/trabalhos/EnANPAD/enanpad_2005/ MKT/2005_MKTA2861.pdf>. Acesso em: 16 out. 2016.

SADE-BECK, L. Internet ethnography: online and offline. International Journal of Qualitative Methods, [S.I.], v.3, n.2, p. 1-14, jun. 2004. <http://ijq.sagepub.com/ content/3/2/45.full.pdf + html>. Acesso em: 16 out. 2016.

WARD, K. J. The Cyber-Ethnographic (Re)Construction of Two Feminist Online Communities. Sociological Research Online, [S.l.], v. 4, n.1, 1999. Disponível em: $<$ http://www.socresonline.org.uk/4/1/ward.html>. Acesso em: 16 out. 2016

WHYTE, W. F. Sociedade de esquina. Rio de Janeiro: Jorge Zahar, 2005. 